\title{
Customer classification in banking system of Iran based on the credit risk model using multi- criteria decision-making models
}

\author{
Khalil Khalilia and Kamal Khalilpour ${ }^{b^{*}}$
}

Department of Management, Mahabad Branch, Islamic Azad University, Mahabad, Iran

\begin{tabular}{l}
\hline C H R O N I C L E \\
\hline Article history: \\
Received December 5, 2015 \\
Received in revised format \\
February 162016 \\
Accepted March 122016 \\
Available online \\
March 142016 \\
\hline Keywords: \\
Risk \\
Risk management \\
Credit risk \\
Customer classification
\end{tabular}

\section{Introduction}

Blocking resources as past and differed due receivables not only reduces bank facilities, but also with negative effects on productivity, makes the access of banks' aims difficult and reduces the speed of economic advancement and flourishing. Although any delay in the return of resources to banks may create trouble for institutions with the shortage of resources, the reduction in the power of giving facilities in banks results in increasing demands of different economic units and leads to more dangerous consequences than bank losses. Accordingly, the use of modern methods of financial management and applying carrots and sticks tools for increasing coordination among different parts have been changed and probably this will consume more power and energy in future.

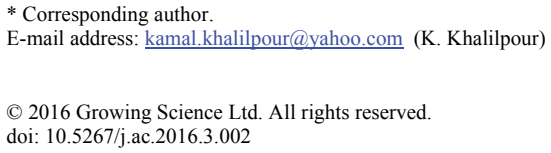

\begin{abstract}
One of the most important factors of survival of financial institutes and banks in the current competitive markets is to create balance and equality among resources and consumptions as well as to keep the health of money circulation in these institutes. According to the experiences obtained from recent financial crises in the world. The lack of appropriate management of the demands of banks and financial institutions can be considered as one of the main factors of occurrence of this crisis. The objective of the present study is to identify and classify customers according to credit risk and decisions of predictive models. The present research is a survey research employing field study in terms of the data collection method. The method of collecting theoretical framework was library research and the data were collected by two ways of data of a questionnaire and real customers' financial data. To analyze the data of the questionnaire, analytical hierarchy process and to analyze real customers' financial data, the TOPSIS method were employed. The population of the study included files of real customers in one of the branches of RefahKargaran Bank in city of Tabriz, Iran. From among 800 files, 140 files were completed and using Morgan's table, 103 files were investigated. The final model was presented and with $95 \%$ of probability, if the next customer's data is entered the model, it will capable of identifying accurately the degree of customer risk.
\end{abstract}




\section{Statement of the problem}

Banks, as financial institutions, which have determining roles in the economy of countries are involved in various kinds of risks in the sense of the uncertainty in financial markets. In financial markets, one of the important risks is associated with investigation, identification, and focus and it maintains significant role in reducing costs, increasing incomes, and consequently increasing profitability. Credit risk is the risk which is probable as the result of the inability of customers to repay loans and credits received; therefore, the concept of risk is the estimation and ranking of customers for granting facilities and providing appropriate solutions to decide a new approach for development of banks. This paper presents a strategy to classify credit applicants as properly as possible and to reduce the probability of not paying facilities according to indicators and parameters affecting customer selection.

All over the world, the banking industry is one of the most important elements in the economy of each country and due to the prevision of diverse financial and credit services, it has a determining role in economic development of counties and can be considered as the driving force as well as accelerating, balancing, and regulating sector of the economy (Hawkins \& Mihaljek, 2001).

A banking activity can occur via giving facilities, but money and capital circulation in the society can put these financial institution at the exposure of different risks, the diversity of these risks and sometimes their intensity are so much that if a financial institution cannot control and manage them in an appropriate way, it will face bankruptcy (Vollmer \& Wiese, 2016). Therefore, regarding the increase in the demand of facilities and the risk available in these types of activities, the validation of those who demand facilities and providing an appropriate model for the mode of paying facilities are main principles of Credit Risk Management in banks and financial institutions in such a way that using instruments of Credit Risk Management particularly validation provide these facilities for banks to be able to decide about giving facilities with more confidence (Packer \& Tarashev, 2011).

The main objective of the present study is to classify customers and predict credit risk management of customers of Refah Bank.

\section{Review of literature}

One of the main activities of banks is to equip and allocate financial resources. Banks can collect resources under names such as loan deposits (current and Interest Free Loan) and investment deposits. The other part of the success and survival of banks is to allocate related financial resources (credits). Banks should allocate limited financial resources as appropriately as possible to produce goods and services. Therefore, granting facilities constitutes a main part of operations of each bank. Commercial banks are interested in the investigation of some main variables in the allocation of credits to their

investors such as dependability, capability and technical competence, financial capacity and credit worthiness, and collateral and financing (Kick \& Pfingsten, 2011; Dima, 2011)

\section{Definition of risk}

Risk means the possibility of occurring dangers or facing with dangers, being damaged, or lost as well as reducing incomes. According to Slovic (2004), risk means the possibility of occurring a damage or loss including financial or non-financial ones due to doing some activities (ShayanArani, 2001). On the other hand, risk is a potential damage or loss which is directly imposed on the income or capital, or indirectly, it emerges from limitations which can reduce banks' abilities for accessing their own financial and business objectives.

There are different kinds of risks on financial market. Credit risk includes market risk, operational risk, legal risk, and risk of venture capital adequacy rate of return. In addition, liquidity risk includes the risk of accuracy exchange rates. 
Banks and financial institutions, due to their nature, are faced with a lot of risks from the beginning, but due to the expansion and diversity of bank activities, researchers have not reached an agreement on different kinds of bank operations; therefore, risks which can be effective on financial institutions can be classified into three groups as follows:

1. Risks on which financial institutions have no control and instead, they are affected by them.

2. Risks on which financial institutions have effects but this effect is very little and instead they are affected by them.

3. Risks which affect financial institutions but financial institutions may use methods and instruments to control and manage them (Asli, 2011).

Among risks which threat banks and financial institutes, credit risks, due to centrality, the dimension of operation, and particularly its sensitivity, are considered as the most important risk factors; therefore, only risks at the third groups on which financial institutions can dominate and control them, using methods and instruments of risk management.

\section{The concept of credit risk}

Credit risk is one of the most important factors of producing risks in banks and financial institutes. Credit risks can be defined in the form of unexpected events which usually occur in the value of properties or debts $(\mathrm{He}, 2016)$. This risk is produced because receivers of facilities have no interest or ability to repay their debts to banks. It can be called as dishonor. In general, there are four traditional indicators considered expansively for determining the amount of credit risks of banks:

- The ratio of past, deferred, and doubtful due receivables to granted facilities;

- The ratio of past, deferred, and doubtful due receivables to properties;

- The ratio of saving of doubtful receivables to granted facilities;

- The ratio of saving of doubtful receivables to whole properties (Ebrahimi \& Daryabar, 2012).

\section{The concept of risk management}

Risk management is a process in which the reduction of damaging effects of an activity is via conscious measures for predicting unexpected events and planning for avoiding them. Risk management means the use of personal and group skills for ensuring the identification of all risks, measuring and performing them in projects. Individuals' consideration of risk mainly is associated with negative effects on timing and costs of projects. Paradigm or model of risk management is a set of tasks, which are available in the form of a series of continuous activities all over the life cycle of a mission. This includes identification of risks, analysis, planning, follow-up, control, and communication.

\section{Different kinds of risk management}

1. Liquidity risk management

2. Market risk management

3. Operational risk management

4. Credit risk management

For credit risk management and realizing its objectives, doing the following cases is vital:

- Screening and monitoring

- Creating long-term relationships with customers

- Loan commitment
- Collateral

- The requirements for compensation

- Credit rationing 
Risk process

Risk management process includes 6 stages. Fig. 1 shows this process.

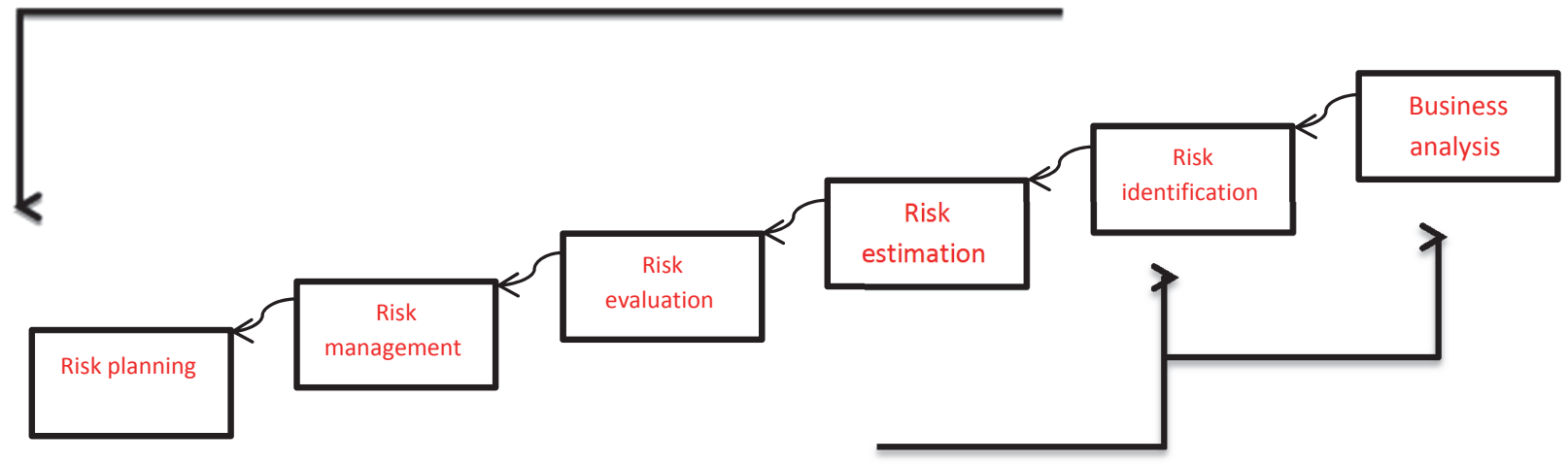

Fig. 1. risk management process (EsmaeilNejadAhangari, 2012: 31)

\section{Ranking and scoring customers}

By having scores, the possibility of measuring credit risks for banks can be provided, and it can be presented appropriate with the credit portfolio, that is, the observable and measurable risks of banks can be amended and modified in relation with different kinds of risks. This issue can be explained via the following equation:

Expected loss $=($ The amount at risk $) \times($ The rate of loss in the event of non-repayment $) \times($ The risk of non-repayment)

The credit scoring system should have the capability of estimating the risk of non-payment. Banks can modify their own portfolio assets credits, and credit customers based on expected loss (Rashidian, 2011: 48).

\section{Criteria and models used for customers' ranking}

One of the most important issues in credit activities is having full information of the credit competency of the other party because information asymmetry among different parties provides the possibility of emerging failures. Ranking models can be divided into two groups:
a. Linear probability model
b. Classification Trees
c. Parametric models
d. Recursive Portioning Algorithms
e. Logit and Probit model
f. K-nearest Neighbors
g. Neural Network
h. AHP
i. Linear Programing
j. Expert Systems (Asli, 2011).

Using such a mechanism, valid customers can be distinguished from invalid ones, and banks' resources move towards those demanders who have more rights for receiving facilities in terms of credit. This mechanism, in addition, regulates the guarantee and collaterals required for granting facilities to customers based on their credit scores and prevents unnecessary rigor and ease towards customers (Rezaei, 2011).

\section{Research method}

In terms of nature and objective, the present study is an applied research; in fact, the aim of an applied research is to obtain necessary knowledge or understanding for determining an instrument by which a certain or known need can be identified. The present study is a correlational research in terms of data analysis. 
Since the present study evaluates both real and legal customers, the population of the real customers includes about 800 credit files of real customers of Refah Bank who use facilities of this bank. But, by considering the evaluated indicators in the present study, only 140 files containing complete information were selected. These files were divided into two groups of creditworthy clients (without arrears) and discredited customers (with arrears). Since collecting and analyzing 140 files were difficult, using Morgan's table, 103 files were selected to being analyzed. In the present research, to collect data, a questionnaire was used.

\section{Research variables}

In the present study, customer credit risk have been referred to as the dependent variable and the following indicators are considered as independent variable which are categorized in two general groups of indicators related to real and legal customers. The selection of variables which have certain relations with the possibility of the borrowers' dishonor is one of the research stages, regarding that identified indicators have no much significance in the domain of the present research; therefore, with coordination with the supervisor and some financial experts and counselors in Refah Bank, those indicators which had the most significance were identified and considered. They are as follows:
1. Applicants' income
3. Education
5. Years of service
7. The type of collateral
9. Applicants' income
11. Education

2. Years of service

4. The type of collateral

6. The value of collateral

8. The duration of the relationship with the bank

10. The average of account balance

12. Years of service

The objective of each bank in analyzing credit risk is that it can identify whether a business unit or institute has the ability to pay its debts timely or not? In the present study, to access this objective, the analytical hierarchy process (AHP) (Saaty, 2004) model was used. The AHP model used in the present study is among models based on scoring. In the present study, the questionnaire of paired comparisons are designed and then, were distributed among experts and professors for identifying the most important indicators via its distributed coefficients and then, questionnaires were collected and analyzed using Expert Choice software and the group AHP model. Then, the obtained coefficients were obtained for each indicators. Next, the study used TOPSIS method for ranking different alternatives (Yoon \& Hwang, 1995).

\section{Data analysis}

The present study was conducted at two levels of real and legal customers. For analyzing data, the TOPSIS and AHP methods were sued for identifying creditworthy and discredited customers. In such a way that first to evaluate the significance coefficients of each indicator, a questionnaire in the form of paired comparisons was developed and distributed among elites and academics and the results were analyzed using Excel software and Expert Choice. Second, the significance coefficient of each indicator was obtained. In the next stage, using the TOPSIS and the calculated CL value for each customer and the degree of farness or closeness of them to the positive idea and negative ideals were divided into two creditworthy and discredited customers. In the present study, to identify and classify real customers into two creditworthy and discredited customers, seven indicators were identified as the most important indicators:

1. Applicants' income

2. Education

3. Years of service

4. The type of collateral
5. The value of collateral

6. The duration of the relationship with the bank

7. The average of account balance 
For mixing the ideas of respondents according to the Group AHP, geometric mean of presented answers was used. After mixing the ideas, the results obtained from analyzing respondents by Expert Choice software indicate that the average of account balance indicator with the significance coefficient 0.270 had the highest importance and other indicators such as the duration of the relationship with the bank with significance coefficient 0.221 , in the second rank, the value of collateral with the significance coefficient 0.185 , in the third rank, the type of collateral with the significance coefficient 0.137 in the fourth rank, years of service with significance correlation 0.088 in the fifth rank, income with the significance coefficient 0.068 in the sixth rank, and education with significance coefficient 0.031 was in the seventh rank. Therefore, the results obtained from the analysis of the questionnaire using the Group AHP are summarized in Table 1 as follows:

Table 1

The results obtained from the analysis of the Group AHP questionnaire

\begin{tabular}{clc}
\hline Rank & Indicators & Significance coefficient \\
\hline 1 & The average of account balance & 0.270 \\
2 & The duration of the relationship with the bank & 0.221 \\
3 & The value of collateral & 0.185 \\
4 & The type of collateral & 0.137 \\
5 & Years of service & 0.088 \\
6 & Income & 0.068 \\
7 & Education & 0.031 \\
\hline
\end{tabular}

\section{Customers' ranking using the TOPSIS model}

After calculating significance coefficient of each studied indicator, regarding real customers based on the TOPSIS model and its stages, the data of 103 individuals of customers of Refah Bank were investigated. Regarding the CL value obtained for each customer, the highest and the lowest CL values were obtained and their means were calculated. Now, to classify customers, the CL calculated for each customer in case that its difference value is higher than the mean CL value and it is positive, it can be considered as a creditworthy customer and in case that the CL value calculated for each customer is lower than the difference value of the CL mean and it is negative, that customer is discredited customer. Finally, classification obtained from the TOSPIS model was matched with the classification available in reality. Table 2 summarizes the results

Table 2

Max, min, and mean for real customers

\begin{tabular}{ccccc}
\hline \multicolumn{2}{c}{$\min$} & Average & \multicolumn{2}{c}{ Max } \\
\hline \multicolumn{2}{c}{0.0824661} & 0.40476886 & \multicolumn{2}{c}{0.72707161} \\
\hline $\mathrm{CL}<0.01$ & $0.11<\mathrm{CL}<0.3$ & $0.31<\mathrm{CL}<0.5$ & $0.51<\mathrm{CL}<0.6$ & $0.61<\mathrm{CL}$ \\
VH & $\mathrm{H}$ & $\mathrm{M}$ & $\mathrm{L}$ & VL \\
Very high & High & Moderate & low & Very low \\
\hline
\end{tabular}

Regarding the obtained CL, a range in the above form can be designed and customer risks can be classified in its format. The results obtained from the TOPSIS method indicated that among 103 cases of predicting classification of customers in comparison with the reality, it predicted 98 cases appropriately and only 5 cases were predicted wrongly. In other words, in case that a new individual is added to this group and his information is put in the equations of this model, with the probability of $95 \%$ it has been appropriately classified and authorizes can with the probability of only $5 \%$ predict the error of creditworthiness or discredit of this new individual. 


\section{Conclusion and suggestions}

Applying scientific methods of decision making and systemic attitude as well as collecting information systematically, scientific evaluation and measurement and optimizing information are among important principles in improving risk management especially in banking industry. The primary objective of the present study was to improve the issue of decision making on granting credits to bank customers. One of the issues related to credit disk management of banks is credit ranking. In other words, the issue of credit ranking and allocating according to the credit degree have involved a lot of centers for credit decision making. In the present study, it was tried to identify main indicators in the field of real customers using bank and academic experts and professionals and using the AHP, the significance coefficients was obtained via paired comparisons and finally, using the TPOSIS method, rankings of applicants' credits in Refah Bank was investigated. After calculating the significance coefficient of each of the studied indicators regarding real customers according to the TOPSIS and its stages, the information of 103 participants were investigated.

The results obtained from executing ranking indicated that it predicted 98 cases appropriately and only 5 cases were predicted wrongly. In other words, in case that a new individual were added to this group and his/her information is put in the equations of this model, with the probability of $95 \%$ it would appropriately classify a new person with the probability of only 5\% predict the error of creditworthiness or discredit of this new individual.

Investigations on crediting in the banking system of Iran indicated a judgment about the credit system. Most banks of Iran have been inattentive to the issue of risk in general and credit risk in particular and they do not have any measure to control general risks of assets and bank debts. The consequences of establishment of judicial systems for granting credits in Iran's bank system are the highness of the amount of resources and doubtful receivables and consequently the reduction in the productivity power of banks.

Risk management is an important element for keeping health of bank activities. The domain of responsibility and the task of risk management as well as its organizational structure are different regarding the size and specialty of banks.

In bigger banks, the responsibility for different parts of credit management are usually burdened on the shoulders of different unis and in smaller banks, the limited number of individuals should do multiple operations.

1. Banks must have certain information systems to empower management in recognition of each type of risk concentration in the form of credit portfolio. The efficacy and content of information should be periodically investigated by line and staff managers in order to ensure about them. In addition, banks should do measures for designing information systems which can analyze their credit portfolio.

2. Credit evaluation institutes and credit ranking have vital roles and statuses in developing the financial supply system because the establishment of these institutes causes an unfair distribution of capitals in the society, enhance the speed and efficacy in allocation of above credit, provide clarity and general confidence, delete personal tastes and human errors from the process of allocating credits, reduce black economy, corruption, and information rent, develop financial markets, develop and enrich credit culture, and at last, by reducing the commitment of financial crimes and improving economic system, it could result in enhancing security and calm as well as public welfare in the society.

3. By designing and performing the management system of credit affairs, the financial institution can achieve appropriate and effective decisions regarding the credit macro policies and credit strategic planning of financial institutions and considering priorities of granting debts in terms of risk and productivity.

4. In addition, the bank management can use the mentioned system as a supportive system of decision making in granting facilities and in all levels of bank operations, i.e. at the total bank 
levels, regions, branch management, branches and even at the level of customers can evaluate the status of bank debts in terms of risk and productivity.

5. The bank should define for customers a credit domain regarding the risk coefficient obtained for customers, and in the defined domain, that it should grant credits to customers and in case of exiting the defined domain, it should enhance the degree of security regarding the type and value of credits.

6. Banks should be active under conditions and principles of granting credit which are properly defined and enjoy necessary health.

7. The bank should have a system for supervising the condition of each credit (regarding the diversity available in this field) such as determining the efficacy of resources and savings.

\section{Acknowledgement}

The authors would like to thank the anonymous referees for constrictive comments on earlier version of this paper.

\section{References}

Asli, Sh. (2011). Credit risk management by looking at the pattern of payment in other countries, providing research and risk control Sepah Bank.

Dima, A. M. (2011). Risk Management in bank, Academy Publish. Org- Risk Assessment and management.

Ebrahimi, M., \& Daryabar, A. (2012). Bank- credit risk management system DEA and logistic regression and neural network. Journal of Finance, 1(2).

Edwards, B. (2004). Credit management handbook. Gower Publishing, Ltd.

EsmaelnejadAhangari, M. (2012). Principles and concepts of risk management. Public relations, Bank Sina.

Hawkins, J., \& Mihaljek, D. (2001). The banking industry in the emerging market economies: competition, consolidation and systemic stability: an overview. BIS papers, 4, 1-44.

He, Y., Xu, Z., \& Gu, J. (2016). An approach to group decision making with hesitant information and its application in credit risk evaluation of enterprises. Applied Soft Computing, 43, 159-169.

Kick, T., \& Pfingsten, A. (2011). The importance of qualitative risk assessment in banking supervision before and during the crisis (No. 2011, 09). Discussion Paper Series 2: Banking and Financial Studies.

Packer, F., \& Tarashev, N. A. (2011). Rating methodologies for banks. BIS Quarterly Review, 39-59.

Rashidian, S. (2011). Customer classification banking network based on credit risk using predictive models and multi-criteria decision-making, (Bank, Financial Management Master's thesis, University of Sanandaj.

Rezaei, A. (2011). Bank customers' credit rating based on data mining methods (case study bank), a Master's thesis management, Payam Noor University, Alborz Province Karaj.

Saaty, T. L. (2004). Decision making-the analytic hierarchy and network processes (AHP/ANP). Journal of systems science and systems engineering, 13(1), 1-35.

ShayanArani, SH. (2001). Non-government risk management and Islamic banking, Islamic banking Proceedings of the Twelfth Congress.

Slovic, P., Finucane, M. L., Peters, E., \& MacGregor, D. G. (2004). Risk as analysis and risk as feelings: Some thoughts about affect, reason, risk, and rationality. Risk analysis, 24(2), 311-322.

Vollmer, U., \& Wiese, H. (2016). Central bank standing facilities, counterparty risk, and OTCinterbank lending. The North American Journal of Economics and Finance, 36, 101-122.

Yoon, K. P., \& Hwang, C. L. (1995). Multiple attribute decision making: an introduction (Vol. 104). Sage publications. 